\title{
CORRELATION OF CERTAIN MENTAL TRAITS IN NORMAL SCHOOL STUDENTS. ${ }^{1}$
}

\author{
BY PROFESSOR HARVEY A. PETERSON, \\ Nashville, Tenn.
}

Investigations of the correlation of mental abilities are fairly numerous, but they are principally of two kinds : first, correlations of proficiency in the various school and college studies, and secondly correlations of the simpler mental processes. A glance at the results will be in place here. There is very little correlation between drawing and the other studies, but there is a considerable amount between the latter studies themselves, usually from 30 to 60 per cent. The surprising feature is that there is as much correlation between the languages and natural science as there is among the languages, and as much between history and natural science as between history and the languages, in short with a few exceptions, "whatever it is that makes for correlation in class standing seems to hold generally for all courses."

The other type of investigation, that of mental processes, has confined itself to quite simple processes. The accuracy shown in bisecting a line, or in striking dots printed on a sheet of paper, or in estimating weights, or in keeping a rhythm is compared with the quickness shown in simple reaction, or in naming colors, or in the association of ideas. Again these are compared with the visual memory for numbers. Often two tests of the same supposed trait, for example accuracy, have been compared with each other, on the theory that correlation among quite different processes was not to be expected. It is significant in this connection that more correlation has been found among the apparently complex processes involved in the school studies, than among the simpler mental processes like those mentioned.

Neither line of investigation has so far given us types of mind, which, however numerous they might be, would be of

${ }^{1}$ The MS. of this article was received May 3, 1908. - Ev. 
use in practical life and in educational theory. For while the investigations of school abilities connect with practical life, they do not give us complete pictures of individuals, even on the school side of life. We do not know how individual persons stand in all their studies, $i$. e., types are lacking. And the studies of mental processes, in the effort to obtain simplicity, have devised tests in many cases removed from life, for example, picking out words containing $\mathrm{r}$ and $\mathrm{e}$, or remembering series of numbers. Further, the higher processes of reasoning, generalizing, comprehending abstract thought, art appreciation, moral sensitiveness, etc., are left untouched.

The following investigation belongs to the second group, but it has sought to bring in some of the so-called higher processes, in particular some which play a leading part in acquiring knowledge. It has also been on the lookout for evidences of types of scholastic mind, and for this reason the effort was made to make the tests somewhat comprehensive. Five tests each taking from 30 to 70 minutes were given to a class of second-year normal and college students. The average age was 2I years. ${ }^{1}$ The normal school students greatly preponderated. The traits tested were accuracy in copying a bibliography, memory for simple connected thought, deductive reasoning, generalizing power, and power to comprehend abstract thought. The tests were given during five of the regular periods of a course in elementary psychology. They were scattered through a half-year at intervals of a week or more, and the first one was not given until two months of the course had passed. Enough time had elapsed for the students to be familiar with the vocabulary involved in the accuracy test, and to know what generalizing meant when that test was given. In all cases the tests were given under the eye of the instructor, to small sections of the class, numbering not over 35 , under conditions which prevented communication and copying.

\section{Accuracy.}

The students did not know that this was a test, as it was given first in the series and before any announcement that a

'A verage deviation, 2.9 years. 
series of tests would be made. The bibliography given below was on the blackboard when they entered the room. They were asked to copy it in their notebooks as it stood, without abbreviating it or making any other changes in it. They were allowed as much time as it took the slowest student to finish, and at the end of the hour the notebooks were collected and the pages containing the test were removed. Thus the exercise was a fair test of how accurate they were in the ordinary pursuit of their courses when they were not on their guard. Inquiry after all the tests had been completed showed that only one person in a section of 35 students suspected that it might be a test. In grading the papers only certain classes of errors were taken into account, such as misspelling the names of authors or the titles of books, errors in the paging, volumes and dates of books and magazines, omission of a dash between the first and last pages or chapters of a reference, omission of the word translation. Errors in punctuation and capitalization were not counted, and in general the aim was to take account of such errors as would tend to hinder the use of the bibliography in a library.

Sensations. - Chapters I.-VII. of An Introduction to Physiological Psychology, by T. Ziehen (transiation), or The Analysis of Sensations, by E. Mach (translation).

The Sense Organs. - The Physiology of the Senses, by J. G. M'Kendrick and W. Snodgrass.

An Experimental Study of Connections of Impression.Chapters V. and VI. of Analytical Psychology, by L. Witmer. Experimental.

Apperception. - The Reading of Words : A Study in Apperception' (in the American Journal of Psychology, I897, VIII., 315-93), by W. Pillsbury; and 'The Apperception of the Spoken Sentence' (in the American Journal of Psychology, I900, XII., 80-130), by W. C. Bagley.

The Physiological Basis of the Emotions. - Chapters IV. and V. of Pleasure, Pain and Esthetics, by H. R. Marshall. Chapters V. and IX. of An Outline of Psychology, by E. B. Titchener. Volume I., Pt. II., ch. IX., of the Principles of Psychology, by Herbert Spencer. 
Feelings of Relutionships. - Pages 243-65 of Vol. I. of The Principles of Psychology, by Wm. James.

Feelings of Meaning. - On the question whether all thoughts and feelings can be classified as general notions, individual notions and abstractions: secs. $89-92$ of $A$ Primer of Psychology, by E. B. Titchener.

\section{Memory.}

The selection given below was read to the class. They were told in advance that it was a memory test in which they would be asked as soon as the reading was finished to recall on paper as much as possible; that recalling the language used was not a part of the test, but they should try to recall as many details or facts as possible. A week later with no warning or refreshing of their memories they were asked to write again as much of the selection as they could recall. In both cases there was no limit on the time, the papers being collected when the last student ceased writing.

Noah Webster.

"Noah Webster was born October 16, 1758, in Hartford, Connecticut, about three miles from the center of the city. His father, Noah Webster, Sr., was a respectable farmer, a deacon in the church, and a justice of the peace. The boy worked on the home farm and attended the village school. When he had reached the age of fourteen, we find him beginning the study of the classics under the instruction of the parish clergyman, and two years later he was admitted to Yale College. The Revolutionary War seriously interrupted the college course, but he graduated with credit in 1778 , and his father gave him an eight-dollar Continental bill, then worth about half its face value, and told him he must henceforth rely on his own exertions.

"It had been young Webster's intention to become a lawyer. The country, however, was impoverished by the war, and his first necessity was to make a living. So he resorted to school teaching. Pedagogy at that time was attended with unusual difficulties. Not only was the war still in progress, but the interruption of intercourse with Great Britain had made schoolbooks very scarce. The need of a home source of textbook 
supply was evident, and in 1782 , while in charge of a school in Orange County, New York, Webster compiled a spelling-book. This was printed at Hartford the next year and gradually won very wide acceptance. During the twenty years its author was engaged in preparing his dictionary, 1807 to 1827 , the profits from that one little school-book furnished the entire support of his family, though his copyright receipts were less than a cent a book. The sales went on increasing up to the time of $\mathrm{Mr}$. Webster's death, at the age of eighty-four. A million copies annually were then being called for, and the total distribution had reached twenty-four millions.

"In his person Webster was tall and slender. To the very end he was remarkably erect, and his step light and elastic. He was enterprising, self-reliant, and very methodical, and a most persevering worker. Besides the monumental labor of making his dictionary, he had much to do with newspapers and magazines, both as editor and contributor, and he wrote a great number of books and pamphlets on literary, historical, medical, religious, scientific, and political subjects, some of which were of very marked value in forming public opinion. He taught school in his early manhood for about ten years, and then, from I 789 to 1793 , was a lawyer in Hartford. During other periods he served as an alderman in New Haven, as a judge in one of the Connecticut courts, and as a member of the Massachusetts legislature. His activity was astonishing in amount and variety, and it was unceasing. Mental exertion seemed to be the native element of his soul."

In grading the papers the selection was marked off into 85 facts or details, and each person's grade was determined by adding together the total numbers of facts he recalled in the first and second recalls. Generalizations were fairly common, e. $g$, he wrote for the newspapers on a number of different subjects. These were allowed I point.

\section{Reasoning.}

In this and the two remaining tests each student had a clear mimeograph copy of the questions before him. In the reasoning exercise the aims were to test the student's sense of the 
truth or falsity of ordinary judgments and his sense of the logical connection of statements. No course in logic was presupposed. The meaning of the terms 'premise' and 'conclusion' was explained and the necessity of giving reasons for one's answer in case an error in the reasoning was thought to be detected was emphasized, but otherwise no further directions were given than those which head the exercise. Seventy minutes was allowed.

A.

State whether the following conclusions are necessarily true or not. If not, where is the error? Point it out. If the reasoning is sound, but the premises false, point out what is false in the premises.

r. The express train alone does not stop at this station; and as the last train did not stop, it must have been the express train.

2. If Parr's pills are of any value those who take them will improve in health; my friend who has been taking them has improved in health; therefore they are of value.

3. Nothing that increases taxation can long be popular. All wars increase taxation, and consequently none of them can be popular very long.

4. If he did not steal the goods why did he hide them, as no thief fails to do?

5. The Greek teacher of oratory and politics, Protagoras, makes an agreement with a pupil, Euathlus, by which the latter is to pay for the instruction which he has received from Protagoras, as soon as he wins his first case; but as he engages in no suits, Protagoras gets nothing, and sues him on that account, confronting him with the following dilemma: "Whatever be the issue of this case, you must pay me what I claim; for if you lose you must pay me by order of the court, and if you win you must pay me by our contract." Euathlus retorts as follows : "Whatever be the issue of this case, I shall not pay you what you claim; for if I lose I am free from payment by our contract, and if I win I am free by order of the court."

6. An Athenian mother urged her son not to enter public life on the following grounds: "If you say what is just, men 
will hate you; and if you say what is unjust, the Gods will hate you. You must say one or the other; therefore you will be hated." The son replied that he ought to enter public life, giving the following reasons: "If I say what is just the Gods will love me; and if I say what is unjust, men will love me. I must say one or the other; therefore I shall be loved."

7. Giving advice is useless. For either you advise a man what he means to do, in which case the advice is useless; or you advise him what he does not mean to do, and the advice is ineffectual.

B.

Solve the following examples :

I. Twelve persons hired a boat for a certain sum. Four of them withdrew without paying, and thus the expense of each of the others was increased by $\$ 2$. What was the rent of the boat?

2. Three men can paint a boat in four days. Two of them can do it in six days. How long would it take the third man working alone?

C.

Prove the following theorems :

I. The diagonals of a rhombus are perpendicular to each other and bisect the angles.

2. Two circles have radii of 8 inches and 3 inches respectively, and the distance between their centers is 15 inches. Find the length of their common tangents.

In grading the reasoning papers no certain amount of credit was allowed for each question. The student's ability was estimated as teachers of English estimate a student's ability to use the English language from a written paper. Certain rules regarding doubtful questions, which cannot be given here, were followed. Liberal credit was allowed for partially correct answers or for differing answers, where there was ground for a difference of opinion. The paper gives opportunity for different degrees of ability. In $A$ the first four and the seventh are relatively easy, the sixth more difficult, and the fifth the most difficult. $\mathrm{B}_{2}$ is harder than $\mathrm{Br}$, and $\mathrm{C}_{2}$ than $\mathrm{Cr}$. As the attempt was made to grade the papers only as good, medium and poor, it is believed that the marks are reliable. Five degrees of ability could prob- 
ably have been distinguished, but the more conservative position seemed the wiser under the circumstances.

\section{Generalizing Power.}

Before beginning this test the meaning of generalizing was explained. This was probably unnecessary as the class had already studied the process during the term. The term 'selectmen' was also explained. Time allowed : 50 minutes.

I. What generalizations can you make from the facts given below? Why is the cloth around the glass zuet? Why is straw put under the saucers in India?

" Water put into a vessel of unglazed clay is kept permanently cool in warm dry air, by the evaporation from the surface of the vessel. A similar result is produced when a glass vessel is employed, if it be wrapped in a wet cloth and placed in a current of air. In some parts of India ice is procured by exposing water at night in shallow unglazed saucers, laid upon ricestraw. More rapid effects may of course be obtained by using instead of water more highly evaporable liquids, such as sulphuric ether. A few drops of ether sprinkled on the bulb of a thermometer, produce an immediate contraction of the contents, which is greater as the temperature of the air is higher. This process, with a quantity of dry oatmeal, or a large surface of sulphuric acid (to absorb the vapor as it is formed) was employed by Sir John Leslie for the purpose of making ice; and is still, with various modifications, the basis of some of the most convenient domestic ice-machines."

2. What general statement or statements can you make which will be true of all the following instances of the way in which Colonial schoolmasters were paid?

In Watertown, Mass., in 168 o the schoolmaster got 25 pounds and the benefit of the Latin scholars. In Newbury, Mass., in 1696 the schoolmaster was offered 30 pounds in country pay by the selectmen provided he demand but 4 pence per week from Latin scholars, and teach the town's children to read, write and cipher without pay. In Lynn, Mass., in 1702 a schoolmaster was allowed 40 pounds by the selectmen, and Latin pupils were charged 6 pence per week. In this case, assuming an average 
of 6 Latin pupils attended the whole year, we see his total wages would be about $\$ 237$. In Hartford, Conn., in 1643 the town agreed that the schoolmaster should receive 16 pounds, that this should be raised by tuition fees of 20 shillings a year per pupil as far as possible, but the town was to make good any deficit. The indigent were free. Salem, Mass., had a subscription for its school, but the town provided for the poor by a rate.

3. What is the difference between plants and animals?

4. What is the difference between the two classes of movements referred to in this selection: If wasps are allowed to come into a room for honey placed there, and if after they enter the window is closed and another window on the opposite side of the room is opened and they are put out at this window, after a number of repetitions of the experience they will leave by the latter window of their own accord. Chickens driven into a shed after nightfall for a number of days will finally go there without driving. Contrasted with these movements are the movements of the human eyelids when solid matter threatens to enter the eye, and the trophic movements of plants, such as the turning of their leaves toward the light when placed in a window.

5. What is the difference between gambling and legitimate business investment?

6. What is the difference between courtesy and gallantry?

The estimate plan of grading the papers was used here. The questions most relied upon in determining the gradec were the first, second and fifth.

\section{Power to Understand Abstract Thought.}

About 40 minutes was allowed for this test.

Study the selection numbered $I$ and tell the meaning of it in your own language. No notice will be taken of papers which quote the selection, even in altered words. Express all the ideas that you get from it. Then do the same with the selections numbered 2, 3 and 4 .

I. "It has been said that protection is the cause of high wages. Our present tariff averages above forty per cent. on the entire amount of dutiable goods; and as a result the price of all articles named in the schedules, both of foreign and domes- 
tic manufacture, is raised in most cases by the entire amount of the tax, since importation continues. Since the list includes nearly every article of comfort or necessity in the family, the laborer must pay a considerable part of his wages to meet this tax. In most cases this increased cost of commodities is far greater than the assumed increase of wages. Hence the laborer is injured, even on the supposition that the claim of protectionists is true. When analyzed, wages are not the dollars received, but the goods which they will buy. Profit is not the money handled, but the sum that is saved."

2. "No one will doubt that men are more possessed by the instinct to fight, to be the winner in serious games and contests, than are women; nor that women are more possessed than men by the instinct to nurse, to care for and fuss over others, to relieve, comfort and console. . . . The fighting instinct is, in fact, the cause of a very large amount of the world's intellectual endeavor. The financier does not think for money, nor the scientist for truth, nor the theologian to save souls. Their intellectual efforts are aimed in great measure to outdo the other man, to subdue nature, to conquer assent. The maternal instinct in its turn is the chief source of woman's superiorities in the moral world. The virtues in which she excels are not so much due to either any general moral superiority or any set of special moral talents as to her original impulse to relieve, comfort and console."

3. By realism we shall mean a belief in the existence of things independent of perceiving minds, and by realism, the contrary belief that nothing exists but minds. The fundamental fallacy of realism lies in its assumption of the existence of primary and secondary qualities in things. By primary qualities they mean those which exist in things independent of the perceiving mind. They are extension in three dimensions, weight, motion and number. By secondary qualities they mean those which are produced by the action of things on our sense organs, such as color, sound, taste, odor, temperature, and so on. But according to this definition of secondary qualities, all the so-called primary qualities are as truly secondary as the secondary ones themselves. For we know nothing of 
their existence, except as we get them through our sense organs.

4. "Motives. There is no need of restricting the word motive to any particular class of feelings. Any mental state may serve as a motive. For a motive to an act is simply any fact which assists to be present and to be approved a mental atate which will have the act as its sequent. A motive against the act is simply any fact which hinders the presence and approval of a mental state which will have the act as its sequent."

As in the third and fourth tests the estimate plan of grading the papers was followed, and only the three grades of ability good, medium and poor were distinguished. The selections vary a good deal in difficulty thus allowing scope for different degrees of ability. The third is the most difficult. The fourth; taken from the text-books in psychology they were then using, is a passage which they were supposed to have studied but it was omitted in the recitations.

\section{REsults.}

Sixty-three persons completed the five tests properly. Thirtythree more took some of the tests but missed others through absence. The percentages of correlation include the latter. In calculating them the grades - given in the form of the total number of errors in the accuracy test, the sum of the total number of facts remembered in the two recalls in the memory test, and in the form of verbal grades in the three other tests - were all changed into their corresponding values in Galton's table of the normal curve of distribution. ${ }^{1}$ The coefficients of correlation were then calculated by the method of unlike signed pairs. They are as shown on next page.

It is needless to say that the figures are much higher than those usually obtained for the simpler mental processes. The next table is a group comparison of the 63 students who completed all five tests. It gives their grade in each test. The subjects are denoted by numbers, and are arranged in three groups with reference to their standing in the reasoning test.

${ }^{1}$ Galton, Francis, Natural Inheritance, p. 205. I am indebted to Professor E. I. Thorndike for assistance in figuring the coefficients of correlation. 


\section{CORFFicinats OF CORREIATION.}

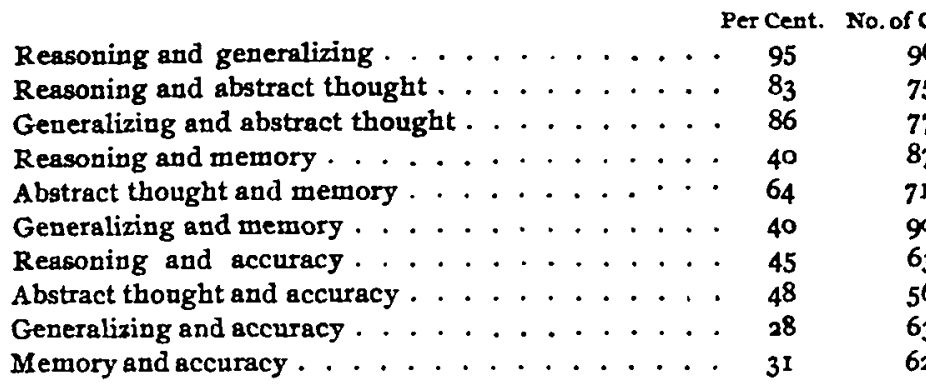

In this way their standing in the various tests may be compared. The verbal grade good in accuracy and memory was obtained by averaging the number of goods in the three intellectual tests which gave $3^{\circ}$, or $4^{8}$ per cent. of the 63 persons concerned. The highest 48 per cent. of the memory and of the accuracy grades were then called good. The terms medium and poor were obtained in the same way. Hence in these two tests the terms are not estimates, but derive their meaning from the three other tests. The table may be read thus: Of the $3^{\circ}$ persons good in reasoning all are good in generalizing, 25 are good in comprehending abstract thought, 20 are good in memory, and of the 24 persons good in reasoning left after deducting the 6 defective in eyesight, 15 are good in accuracy. Of the remainder more are medium than poor. Of the $I 7$ persons poor in reasoning $\mathrm{I} 2$ are poor in generalizing, I 3 in abstract thought and 8 in memory, and of the 16 poor in reasoning left after deducting $I$ defective in eyesight, 6 are poor in accuracy, etc. We find in this group comparison considerable evidence for the existence of three major types of mind, from the point of view of the traits investigated: First, persons good in the three intellectual traits, secondly, those poor in them, and thirdly those between the two extremes in all three traits. The term type is used to denote stages along a continuous line.

But the types tend to be more comprehensive than that. Persons who are superior in the three intellectual traits are apt to have better memories, and obversely. This is shown both by the group comparison and by the average of 48 per cent. correlation between memory and the intellectual traits. There 
is some tendency for even accuracy to vary with the three mentioned (40 per cent. average correlation).

Grout Comparison.

Good in Reasoning.

\begin{tabular}{|c|c|c|c|c|}
\hline Subject. & Generalizing. & Abstract Thought. & Memory. & Accuracy. \\
\hline $\begin{array}{r}1 \\
2 \\
3 \\
4 \\
5 \\
6 \\
7 \\
8 \\
9 \\
10 \\
11 \\
12 \\
13 \\
14 \\
15 \\
16 \\
17 \\
18 \\
19 \\
20 \\
21 \\
22 \\
23 \\
24 \\
25 \\
26 \\
27 \\
28 \\
29 \\
30 \\
\end{array}$ & 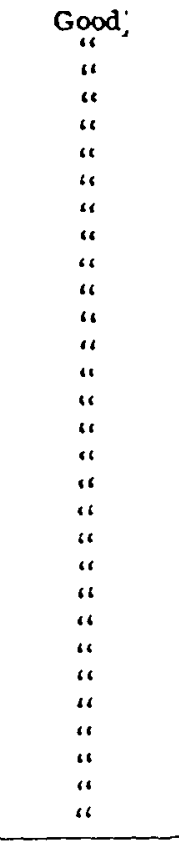 & 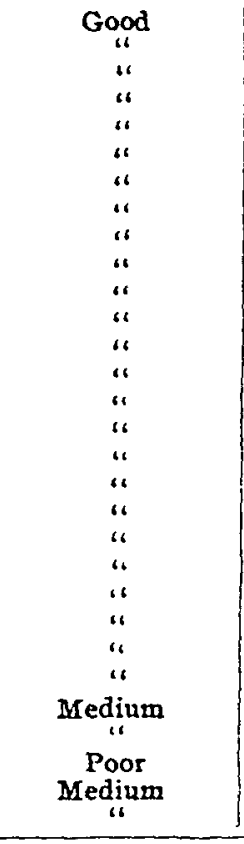 & 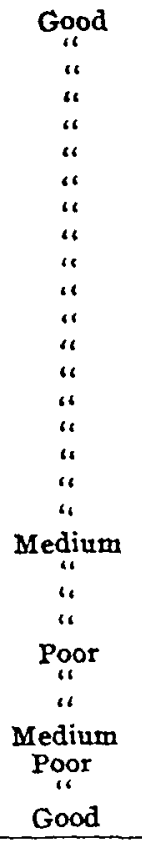 & 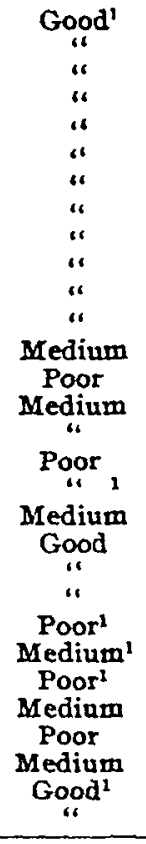 \\
\hline \multicolumn{5}{|c|}{ Poor in Reasoning. } \\
\hline $\begin{array}{l}31 \\
32 \\
33 \\
34 \\
35 \\
36 \\
37 \\
38 \\
39 \\
40 \\
41 \\
42 \\
43 \\
44 \\
45 \\
46 \\
47\end{array}$ & 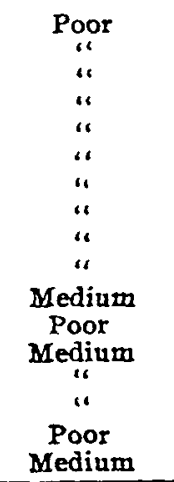 & 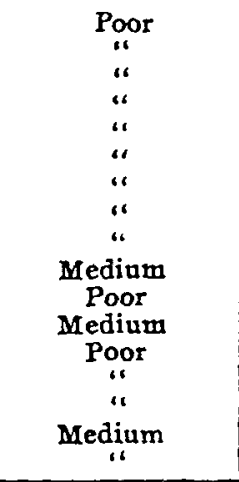 & $\begin{array}{c}\text { Poor } \\
" ، \\
" ، \\
\text { M" } \\
\text { Medium } \\
\text { "“ } \\
\text { Good } \\
\text { Poor } \\
\text { Medium } \\
\text { Poor } \\
\text { Medium } \\
\text { Good } \\
\text { G" }\end{array}$ & $\begin{array}{c}\text { Poor } \\
" “ \\
\text { Medium } \\
\text { Good } \\
": \\
\text { Poor } \\
\text { Good } \\
\text { Medium" } \\
\text { Good } \\
\text { Poor' } \\
\text { Medium } \\
\text { Good } \\
\text { " } \\
\text { Medium } \\
\text { Poor }\end{array}$ \\
\hline
\end{tabular}

1 Defective eyesight. 
Group Comparison.-Continued.

Medium in Reasoning.

\begin{tabular}{|c|c|c|c|c|}
\hline Subject. & Generalizing. & Abstract Thought. & Memory. & Accuracy. \\
\hline $\begin{array}{l}48 \\
49 \\
50 \\
51 \\
52 \\
53 \\
54 \\
55 \\
56 \\
57 \\
58 \\
59 \\
60 \\
61 \\
62 \\
63\end{array}$ & $\begin{array}{c}\text { Medinm } \\
\text { "، } \\
\text { Good } \\
\text { “" } \\
\text { “" } \\
\text { Poor } \\
\text { “" } \\
\text { Medium } \\
\text { “" } \\
\text { Poor } \\
\text { Good } \\
\text { Poor }\end{array}$ & $\begin{array}{c}\text { Medinm } \\
\text { “" } \\
\text { “" } \\
\text { “" } \\
\text { "، } \\
\text { “" } \\
\text { Poor } \\
\text { "، } \\
\text { Good } \\
\text { Poor }\end{array}$ & $\begin{array}{c}\text { Good } \\
\text { "“ } \\
\text { "“ } \\
\text { "“ } \\
\text { Medium } \\
\text { Poor } \\
\text { Good } \\
\text { Medium } \\
\text { Poor } \\
\text { Medium } \\
\text { Poor } \\
\text { "“ } \\
\text { Medinm } \\
\text { Poor }\end{array}$ & $\begin{array}{l}\text { Poor } \\
\text { Medium } \\
\text { Good } \\
\text { "“ } \\
\text { Medium } \\
\text { Good } \\
\text { “" } 1 \\
\text { Poor } \\
\text { Medium } \\
\text { Good } \\
\text { Poor } \\
\text { ““ } \\
\text { Good } \\
\text { Medium } \\
\text { Poor }\end{array}$ \\
\hline
\end{tabular}

The group comparison also affords ample evidence for the existence of some minor types often assumed by practical experience. Among these are the bright but careless and the dull but painstaking types. One student whose reasoning and generalizing abilities and power to grasp abstract thought are unquestioned wrote in the accuracy test 'Witner' for Witmer, 'Titchner' for Titchener, 'chapters V. and VII.' for V. and VI., and omitted one line of text resulting in"giving a wrong name to a book; and there were many others similar, if less extreme. On the other hand 7 of the 17 poor in the intellectual traits are painstaking enough to rank good in accuracy. Still another pair of minor types are those who in memory rise above or fall below their standing in the intellectual traits.

In accounting for the large percentages of correlation it may be said that the grades in the reasoning, generalizing and abstract thought tests are estimates of one person only, who might have been influenced by a preconceived theory, or by a preconceived opinion of the abilities of the persons tested, inasmuch as they had been in his class for two months. The possibility of this is not denied. The writer was on his guard against it always. The papers were graded by sets of a kind, $e . g$., accuracy, and not all of the papers of one student at a time. On the other hand the coarseness of the grading in three tests

'Defective eyesight. 
and the method of calculating the coefficients underestimates the real correlation.

In conclusion the question is pertinent: What abilities have been tested? For the whole tenor of previous investigations has been toward the opinion that there is no such thing as the trait accuracy or the power to comprehend abstract thought, but on the contrary there are as many kinds of accuracy as there are occupations to be accurate in. A person may have considerable acumen in comprehending the psychological differences of the sexes and their consequences, and very little in grasping the effects of a high tariff on wages. There is however a mass of experiences which may be fairly assumed to be the common possession of all normally constituted persons of eighteen years of age or over who have reached the second year of a normal school course requiring two years of high school work for entrance. In framing the tests the writer endeavored to keep well within these limits, and it is believed with the possible exceptions of the questions on the tariff and on evaporation, he was successful. It was not necessary to solve the Protagorean dilemma to secure a grade of good in reasoning. For testing the five abilities (or five kinds of abilities, if they are plural) in this elementary way it is believed that a large number of different materials are equivalent. If a person of the maturity and training described cannot make valid generalizations from the questions about the pay of schoolmasters and the difference between gambling and legitimate business investment, it is safe to say he is deficient in what is ordinarily meant by generalizing, namely picking out elements common to a group. Or again, if there is a memory for dates, another for names, and another for simple commonplace statements, and if it is possible for a person to be good in one and poor in others, it is also possible to regard the sum of them as a unity, and the passage used in the memory test is a fair elementary test of this aggregate of abilities.

But another phase of the question appears. It may be said that the reason why there is so much correlation is that to a large extent they all test the same abilities. The power to understand abstract thought for example may be claimed to be 
required in all, accuracy excepted perhaps, and memory certainly enters into all five to some extent. Even if this were true, it would still be possible ' 0 isolate a kind of ability by increasing the demands made upon one and lessening the demands made upon the others, and the tests have done this. But the claim is not true to any considerable extent, as examination of the material used in the tests would show. In the memory test the demand made upon the power to grasp abstract thought is so small compared to the tax upon the memory that it may be neglected. The reasoning test makes heavy demands upon two abilities, judgment and syllogistic inference. No generalizing is required, and not much power to follow abstract thought except in the geometry questions, which few persons reached. The generalizing test makes large demands upon the power to abstract elements common to a group and a small demand upon memory. There are some inferences which may occur in the abstract thought test, but the peculiarity of this test is the absence of illustrations. Success or failure in it depends upon one's ability to interpret its generalized phraseology by means of his concrete experiences rather than upon the inferences which may be involved.

To sum up the matter, then, each test involves unquestionably not one but several kinds of abilities, but there is a predominance of one kind in each test, and it is this kind which the test makes a trial of. Nor are the results less useful because of this fact of compositeness. To go beyond this and discover the identical abilities in the various traits, which the correlations lead us to assume the existence of, is outside the limits of our present purpose. 